\title{
The Impact of a Low Bias in Snow Water Equivalent Initialization on CFS Seasonal Forecasts
}

\author{
Patrick D. Broxton, Xubin Zeng, AND Nicholas Dawson \\ Department of Hydrology and Atmospheric Sciences, The University of Arizona, Tucson, Arizona
}

(Manuscript received 7 February 2017, in final form 17 July 2017)

\begin{abstract}
Across much of the Northern Hemisphere, Climate Forecast System forecasts made earlier in the winter (e.g., on 1 January) are found to have more snow water equivalent (SWE) in April-June than forecasts made later (e.g., on 1 April); furthermore, later forecasts tend to predict earlier snowmelt than earlier forecasts. As a result, other forecasted model quantities (e.g., soil moisture in April-June) show systematic differences dependent on the forecast lead time. Notably, earlier forecasts predict much colder near-surface air temperatures in April-June than later forecasts. Although the later forecasts of temperature are more accurate, earlier forecasts of SWE are more realistic, suggesting that the improvement in temperature forecasts occurs for the wrong reasons. Thus, this study highlights the need to improve atmospheric processes in the model (e.g., radiative transfer, turbulence) that would cause cold biases when a more realistic amount of snow is on the ground. Furthermore, SWE differences in earlier versus later forecasts are found to much more strongly affect AprilJune temperature forecasts than the sea surface temperature differences over different regions, suggesting the major role of snowpack in seasonal prediction during the spring-summer transition over snowy regions.
\end{abstract}

\section{Introduction}

Snow has a large influence on the energy and water cycles between the land and atmosphere. For example, it influences the reflectance of solar radiation, insulation of the soil from the atmosphere, infrared radiation emissivity, and surface roughness. These effects can be felt even after snowmelt, providing a potential source of predictability at seasonal and subseasonal time scales (Peings et al. 2011; Orsolini et al. 2013). Not only does the timing and magnitude of snowmelt influence streamflow, soil moisture, and vegetation health well into the summer, but there can be a link between regional snow cover and subsequent climate patterns as well. For example, some studies have found linkages between snow cover and summertime rainfall (e.g., Hahn and Shukla 1976; Gutzler and Preston 1997). In addition, numerous studies have pointed out the potential impacts

Supplemental information related to this paper is available at the Journals Online website: https://doi.org/10.1175/JCLID-17-0072.s1.

Corresponding author: Patrick Broxton, broxtopd@email. arizona.edu of snow in the Arctic on atmospheric circulation, both locally (over the snow cover) and regionally (e.g., Cohen and Entekhabi 1999; Clark and Serreze 2000; Yang et al. 2002; Gong et al. 2004), and declining snow cover over high latitudes in the Northern Hemisphere contributes to amplification of warming over the Arctic and can cause weather changes even in the midlatitudes (Francis et al. 2009; Cohen et al. 2014).

Despite this importance, the quantification of snow remains a challenge for global modeling systems (Broxton et al. 2016b; Mudryk et al. 2015), especially for operational weather and climate models, such as those used at the National Centers for Environmental Prediction (NCEP). In particular, the amount of SWE initialized in forecast models at NCEP has been found to be generally too low (Dawson et al. 2016). This is because the snow initialization uses data that has too shallow snow, as well as unrealistic assumptions about snow density, which combine to give initialized SWE estimates that are far too low (Dawson et al. 2016; see section 3a below for a brief summary of these findings). Poor snow initialization presents a challenge for seasonal forecasting, in particular, because the effects of poor snow initialization can last through the forecast period: if snow is initialized to be too shallow, it often remains too shallow for much the forecast 
period. Furthermore, shallow snowpack tends to melt much more quickly than deep snowpack, so forecasts that have too little snow tend to have too early melt.

Another consideration is that initialized snow amount, for a particular date, is often different than the modeled snow amount that is generated by an earlier forecast. This means that forecasts made at different times will be different. Normally, this would not be a problem as the initialization of forecast models through assimilation of new data typically means that later forecasts (i.e., those with shorter lead times) are more accurate than earlier forecasts (i.e., those with longer lead times). This is true of both short-term forecasts (Krishnamurti et al. 1994) as well as seasonal forecasts (Chen et al. 1995; Koster et al. 2004; Douville 2010). However, in the case of snow, poor initialization means that later forecasts do not necessarily predict SWE better than earlier forecasts. In fact, the opposite may be true if the initialized snow amount is worse than what the forecast model produces.

The question is this: How much does this inconsistency affect other forecast model quantities? The transition to snow-free conditions, in particular, can have dramatic affects for quantities that are sensitive to the reflectance of incoming radiation. Changes in albedo associated with melting snow directly affects radiative transfer at the surface, as more incoming solar radiation is absorbed by snow-free surfaces. This alters the surface energy balance and affects the transfer of sensible and latent heating between the surface and the atmosphere, leading to changes in near-surface air temperature (Mote 2008; Betts et al. 2014). The transition from snow-covered to snow-free conditions can also affect the transfer of energy to the subsurface. Because snow is a good insulator, a thick snowpack can keep the wintertime soil temperature significantly warmer than it would otherwise be without snow (Decker et al. 2003). Finally, snowmelt provides a substantial hydrologic input and can affect surface runoff and soil moisture for months. Any inconsistency among forecasts involving snow may lead to inconsistencies for these other variables as well.

In this study, we investigate the effects of the low bias of the SWE initialization on other quantities in seasonal forecasts using NCEP's Climate Forecast System (CFS; Saha et al. 2006; 2014). Our goal is to use the extensive dataset of existing CFS output to demonstrate how poor snow initialization affects subsequent forecasts. Specifically, we use $28 \mathrm{yr}$ of retrospective forecasts generated using the same forecast system as version 2 of the operational CFS (CFSv2; Saha et al. 2014). We also seek to isolate the impact of snow from potential impacts from other factors (e.g., the ocean), which will motivate future sensitivity tests using CFS with different initial snow conditions.

\section{Data and methods}

CFSv2 is a coupled land-atmosphere-ocean-sea ice model that uses the NCEP Global Forecast System atmospheric model, the Geophysical Fluid Dynamics Laboratory Modular Ocean Model (version 4), a twolayer sea ice model, and the Noah land model. The atmospheric model in CFS has a resolution of T126 $\left(\sim 0.9375^{\circ}\right)$. CFSv2 (which has been operational since 2011) supersedes an older version of CFS (version 1), which has been operational since 2004. Here, we use the hindcasts that are generated as part of the CFS Reanalysis and Reforecasts (CFS-RR). These hindcasts (which span from 1981 to 2009) are generated with the same model that is used in the operational CFSv2.

Initial conditions for the CFS-RR hindcasts are provided by the CFS Reanalysis (CFS-R; Saha et al. 2010). CFS-R also uses a global coupled land-atmosphereocean-sea ice model, although the model resolution is higher (T382; $38 \mathrm{~km})$. The sea ice and ocean models in CFS-R and CFS-RR are identical, but there are a few minor differences between the land and especially atmospheric models between CFS-R and CFS-RR (Saha et al. 2014). The similarities between CFS-R and CFSv2 (and hence CFS-RR) are by design and are meant to make the CFS-R as consistent with CFSv2 (and CFS-RR) as possible (Saha et al. 2014).

Despite the similarities between CFS-R and CFS-RR, the fact that CFS-R incorporates observational data leads to unavoidable inconsistencies with CFS-RR. Importantly, for this study, CFS-R incorporates external gridded snow data from the Air Force Weather Agency (AFWA; Air Force Weather Agency 2013). AFWA snow depth data are used to constrain the CFS-R snow depth analysis: each day, the CFS snow depth data are constrained to fall within a range of one-half to twice the AFWA data (Saha et al. 2010). Then, snow is removed or added using a snow cover mask (again, derived from external data). Furthermore, this snow depth analysis is converted to SWE analysis using an unrealistically low global constant snow density $\left(100 \mathrm{~kg} \mathrm{~m}^{-3}\right)$. This method of snow data assimilation has been shown to produce SWE estimates that are far too low (Dawson et al. 2016), and indeed, CFS-R depicts less snow than many other major modeling systems (Broxton et al. 2016b). Therefore, the SWE in CFS-R is much less than that which would be predicted by a CFSv2 CFS-RR forecast.

Here, we use $28 \mathrm{yr}$ of CFS-RR data (from 1 October 1982 to 30 September 2010) to assess the sensitivity of CFSv2 forecasts to SWE being consistently initialized too low through the winter. It includes four CFS-RR reforecasts every five days (i.e., 0000, 0600, 1200, and 
1800 UTC forecasts are available from 1 January, 6 January, etc.) for the entire period, and the archived output from each model forecast contains 6-hourly time series of model variables going out to 9 months. In this study, we only obtained the first available day of model forecasts for each month from January to April (those made on 1 January, 5 February, 2 March, and 1 April). We obtained a large number of variables for each forecast, but after extensive analysis this study focuses on SWE, the difference between incoming and outgoing shortwave radiation, sensible heat $(\mathrm{SH})$ flux, latent heat (LH) flux, soil moisture (from the top $10 \mathrm{~cm}$ of soil), sea surface temperatures (SSTs), 2-m air temperature (T2m), sea level pressure (SLP), 500-hPa geopotential height (Z500), and precipitation rate (PPT).

For each year, the forecasts from different months are compared to each other by differencing the ensemble of the first four forecasts from the different months (i.e., the average of the four 1 January forecasts are compared with the average of the four 1 April forecasts). In many cases, we focus on the 3-month forecast period that captures snowmelt and the period immediately subsequent to snowmelt in the high northern latitudes (April-June). That is, the AprilJune period from the 1 April forecasts are compared with the April-June period from the 1 January forecasts. For the purposes of this study, focusing on this extended period during snowmelt is advantageous for two reasons. First, this is when the effects of poor snow initialization on other model quantities are maximized (i.e., during snowmelt; Xu and Dirmeyer 2011). Second, the integration period is long enough that the effects of atmospheric memory (of $\sim 2$ weeks) have relatively little influence on the forecasts for the entire period. This makes it simpler to isolate whether the effects on other model variables are caused by snow initialization, atmospheric state, or ocean state. We make use of all $28 \mathrm{yr}$ of CFS reforecasts by either taking the average of the $28 \mathrm{yr}$ of CFS-RR data (i.e., finding the difference between the average of a particular variable for April-June from the 1 April forecasts and the average of that variable for April-June from the 1 January forecasts) or by finding how the interannual variability of a particular model variable correlates to another.

In addition to the CFS-RR data, this study also uses gridded observation-based SWE and near-surface air temperature data as reference datasets. The SWE data (Broxton et al. 2016a) are based on high-quality PRISM precipitation and temperature data over the conterminous United States (CONUS). It uses an empirical temperature-index model (derived from in situ observations) combined with thousands of SWE and snow depth observations from the National Weather Service Cooperative Observer (COOP) network and the National Resource Conservation Service Snow Telemetry (SNOTEL) network. The dataset is generated by interpolating differences in SWE, normalized by snowfall minus snow ablation, between the station observations and the model estimates. Our data have been tested extensively; most notably, they have been shown to perform well in three significant respects. First, when predicting SWE data between points, our method of interpolation of normalized SWE has been shown to produce much smaller errors than other interpolation methods using SWE itself (Broxton et al. 2016a). In addition, our method is very robust, as interpolation errors are similar regardless of whether a small or large number of stations are used for the interpolation (Broxton et al. 2016a). This is also true of the gridded SWE estimates produced from the interpolation, which are very similar regardless of the number stations used (Broxton et al. 2016b). Finally, the coverage of snow in our SWE data closely matches the Interactive Multisensor Snow and Ice Mapping System (IMS) snow cover data, which are largely based on independent satellite data (Broxton et al. 2016b).

For CFS evaluations, the gridded temperature data come from the global hourly $0.5^{\circ}$ land surface air temperature dataset of Wang and Zeng (2013) by merging the Modern-Era Retrospective Analysis for Research (MERRA) reanalysis data with the station-based Climatic Research Unit (CRU) data. This dataset is constructed by spatially downscaling the hourly MERRA data to $0.5^{\circ}$ resolution, and then bias correcting the data such that monthly maximum and minimum temperatures match the CRU data.

Note that the resolution of these data products, 2.5 arcminutes for the Broxton et al. (2016a) and $0.5^{\circ}$ for the Wang and Zeng (2013) data, is different than the CFS data, and even among the CFS data the resolution of different model outputs varies according to whether it is output from the land model component, atmospheric component, or the ocean model component of CFS. The land model output (in this case, SWE, incoming and outgoing shortwave radiation, $\mathrm{SH}, \mathrm{LH}$, and $\mathrm{T} 2 \mathrm{~m}$ ) has a resolution of $\sim\left(0.94^{\circ} \times 0.95^{\circ}\right)$, the output of the atmospheric model has a resolution of $1^{\circ} \times 1^{\circ}$, and the output of the ocean model (in this case, SST) has a resolution of $0.5^{\circ} \times 0.5^{\circ}$. For comparison, each product is put onto a common $1^{\circ} \times 1^{\circ}$ grid (to roughly match the output of the land surface and atmosphere models) by finding an aerial average of higher-resolution data [from Broxton et al. (2016a) and Wang and Zeng (2013) and the ocean model output) or bilinear interpolation of the land model output. 

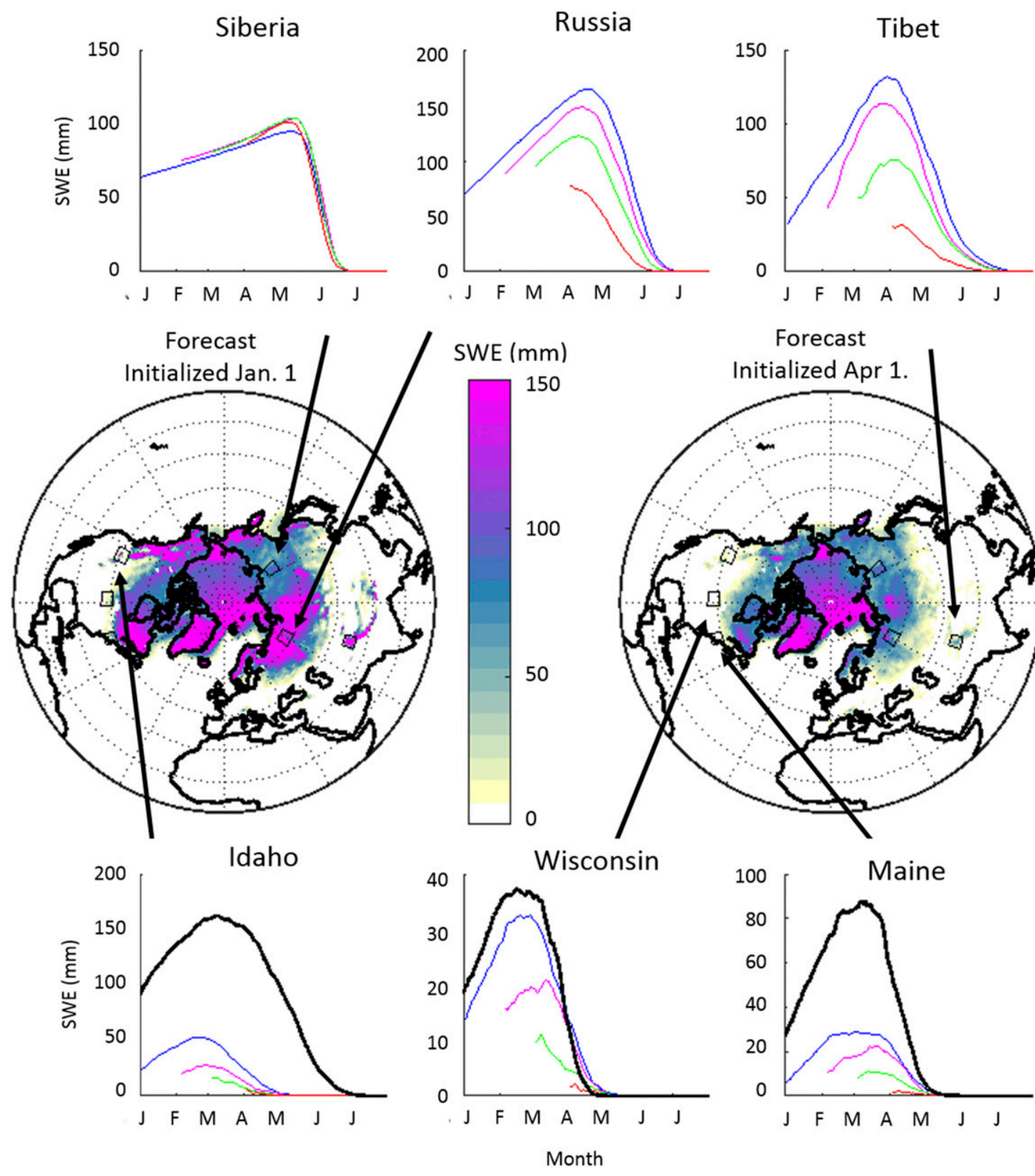
Forecast
Initialized Apr 1

I

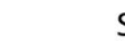

SWE (mm)
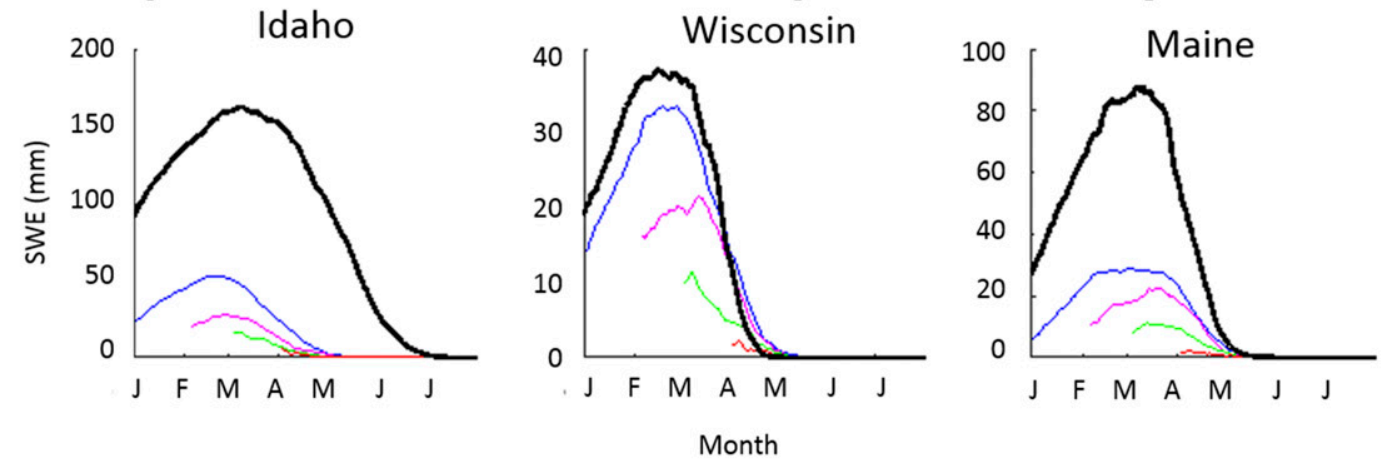

Forecast Initialized:

- Jan 1

- Feb 5 - Mar 2

Apr 1

- Obs

FIG. 1. (middle) Spatial maps of average SWE (1982-2009) on 1 April from the (left) 1 January and (right) 1 April forecasts. (top), (bottom) SWE time series for each $5^{\circ} \times 5^{\circ}$ box indicated in the maps for the forecasts from 1 January (blue), 5 February (magenta), 2 March (green), and 1 April (red) averaged from 1982 to 2009. The thick black lines in the bottom panels show the time series of observed SWE values from Broxton et al. (2016a) averaged for the same period.

\section{Results}

a. CFS snow simulations initialized at different times

In general, CFS-RR forecasts initialized earlier in the winter predict much more snow than simulations initialized later in the winter. This is because the later forecasts are generally initialized with less SWE than is depicted in the earlier forecasts. For example, the middle panels in Fig. 1 show that across much of the Northern Hemisphere, forecasts initialized on 1 January predict higher SWE for 1 April than what is used to initialize forecasts made on 1 April. In fact, across the Northern Hemisphere, 1 April SWE from the 1 January forecasts is more than 2 times as large as that from the 
1 April forecasts for $53 \%$ of the area that is snow covered on 1 April.

In our recent study (Dawson et al. 2016), we found that poor SWE initialization in CFS has two primary causes. First, the snow initialization relies on AFWA snow depth data, which have too little snow in many areas. This, by itself, would cause the initialized snowpack to be too shallow in the CFS, although this problem is compounded by the use of a spatially and temporally constant snow density of $100 \mathrm{~kg} \mathrm{~m}^{-3}$ to convert snow depth to SWE that is then used for the initialized snow state. This constant snow density is appropriate for freshly fallen snow, but can be a factor of 2 or more too low for snow that is sitting on the ground. Although the effects of the poor quality of the assimilated AFWA snow depth data on CFS initialization is partially mitigated by the fact that CFS does not assimilate it if the forecast snow depth is between one-half to twice the AFWA data (otherwise, it is set to one-half or twice the AFWA data), the initialized SWE is still derived by converting snow depth to SWE using the constant snow density. The net result is that initialized snow depth in CFS was found to be $13 \%$ to $87 \%$ of observationally derived snow depth data, and initialized SWE was between $3 \%$ and $51 \%$ of observationally derived SWE data over select areas over the United States (Dawson et al. 2016).

At any rate, the forecasts initialized later in the winter continue to have less SWE for the remainder of the season than the forecasts initialized earlier, resulting in earlier snow-free conditions in the later forecasts. The time series plots in Fig. 1 show that, for selected $5^{\circ} \times 5^{\circ}$ areas in North America and Asia, forecasts initialized on 1 January have more SWE for the remainder of the winter than forecasts made on 5 February, which have more SWE than forecasts made on 2 March, and so on. As a result, later forecasts not only depict less snow on the ground but, in many cases, also an earlier melt out date. Of the six locations shown in Fig. 1, five have dramatically less SWE in later forecasts than earlier ones, and snow-free conditions that develop as much as one month earlier in the later forecasts.

Snow has a strong influence on land-atmosphere interactions through its impact on the amount of radiant energy that is absorbed, not to mention its large role as a hydrological storage and its ability to insulate the ground underneath the snow. Therefore, in the following sections, we address this question: How are other forecast quantities affected by the large difference between the amount of snow depicted in the earlier forecasts (e.g., those made on 1 January) and that depicted in the later forecasts (e.g., those made on 1 April)? In sections $3 \mathrm{~b}$ and $3 \mathrm{c}$, we examine these forecast differences in detail, and in section $3 \mathrm{~d}$, we use other data sources to assess how snow initialization affects the accuracy of CFS forecasts.

\section{b. The impact on other model variables}

Just like there is a large difference of the amount of snow depicted in earlier versus later forecasts, there are also large differences in other quantities that would be directly impacted by the presence of snow on the ground between the earlier and the later forecasts. For example, Fig. 2 shows that for the 3-month period (1 April30 June), SWE and soil moisture (SM) from the forecasts initialized on 1 April (henceforth referred to as "1 April forecasts") are lower than those from the forecasts initialized on 1 January (henceforth referred to as "1 January forecasts"), while net (incoming minus outgoing) shortwave radiation ( $\mathrm{SWn}$ ), $\mathrm{SH}, \mathrm{LH}$, and T2m from 1 April forecasts are higher than those from 1 January forecasts. All of these factors are consistent with what would be expected from having less snow in 1 April forecasts. SWn would be higher because less shortwave radiation is reflected when there is less snow. SM would be lower because not only is there less water contributed from a thinner snowpack but also the snow melts earlier, allowing more time for the soils to dry out. $\mathrm{SH}$ would be higher because snow-free ground heats up much more than the snow surface. The impact of having less snow in 1 April forecasts on LH is more complicated, as LH is higher in 1 April forecasts (than in 1 January forecasts) in northern Eurasia and parts of eastern North America, but it is the same or lower in other locations. In general, LH is strongly affected by net radiation flux (energy source) and soil moisture (water source). In some areas, LH may be higher because of the higher SWn (and hence higher net radiation) when the soils are relatively wet; however, in other areas the soils would dry out faster due to limited snowmelt, thus reducing LH. Finally, T2m is typically higher over snow-free surfaces because the ground is warmer. These influences are discussed in greater detail in section 4. Note that most of these differences appear over land, although differences are also present over the sea ice-covered region (e.g., in the Canadian Archipelago and the ice margin north of Scandinavia) due to changes in sea ice extent between 1 January forecasts and 1 April forecasts.

Most of these quantities diverge substantially between 1 January forecasts and 1 April forecasts during or following the snowmelt period. The first two columns in Fig. 3 confirm this to be the case for a $5^{\circ} \times 5^{\circ}$ box (located over northwest Russia in Fig. 1). The largest differences involving all quantities are highest during the period of snowmelt (May and June; second column 

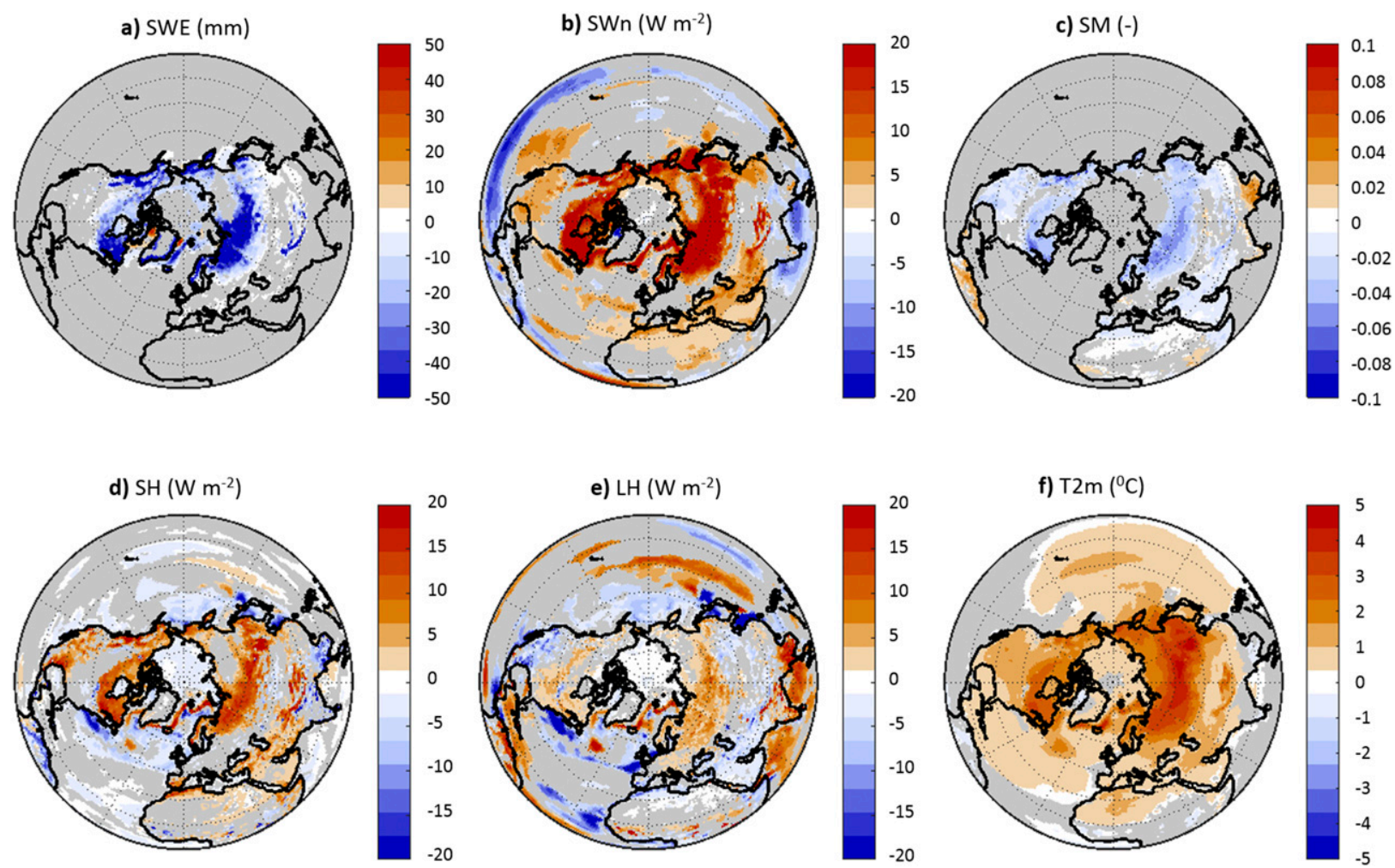

FIG. 2. Spatial maps showing the differences (averaged for all years 1982-2009) of April-June values of (a) SWE, (b) SWn, (c) SM, (d) $\mathrm{SH}$, (e) LH, and (f) T2m between 1 April and 1 January forecasts. Blue colors indicate that the 1 April forecasts predict lower values and red colors indicate that the 1 April forecasts predict higher values than 1 January forecasts. SWn is computed as incoming minus outgoing shortwave radiation and is always positive; upward fluxes of LH and SH are positive. Areas where the differences are not significant (using a two-tailed two-sample $t$ test with a $p$ value of 0.01 ) are shaded gray.

of panels in Fig. 3). In this region, snow melts 2 weeks earlier on average in 1 April forecasts than in 1 January forecasts, and this also seems to be reflected in a 1-2-week lag of increases in $\mathrm{SWn}, \mathrm{SH}$, and $\mathrm{LH}$ and decreases in SM that occur during or immediately following snowmelt (first column of panels in Fig. 3). T2m also diverges significantly during snowmelt, although it also appears that biases involving $\mathrm{T} 2 \mathrm{~m}$ can persist later into the summer as well (row 6, column 2 of Fig. 3).

The link between the lower SWE and earlier snowmelt in 1 April forecasts and the higher values of AprilJune SWn, SH, LH, and T2m and lower SM in 1 April forecasts relative to those from 1 January forecasts is also supported by the fact that there are statistically significant relationships between the 1 April SWE difference between 1 April forecasts and 1 January forecasts (denoted as "dSWE on 1 April") and the difference of the above quantities for April-June between the two forecasts (denoted as "April-June dX" where X could be SWE, SWn, SM, SH, LH, or T2m). Years when dSWE on 1 April is larger have higher absolute magnitudes of April-June dSWE, dSWn, dSM, dSH, and d2M than years when dSWE on 1 April is smaller (third column of Fig. 3). Unlike the other quantities, AprilJune dLH shows almost no correlation with dSWE on 1 April. Note that all of the relationships shown in the third column of Fig. 3, except for that involving $\mathrm{LH}$, have $p$ values of less than 0.01 .

Figure 4 shows that there are many areas across the Northern Hemisphere with a strong positive relationship between dSWE on 1 April and April-June dSWE: years with less initialized SWE in 1 April forecasts relative to 1 January forecasts lead to more negative values of April-June dSWE (note that this is true over land as well as over sea ice near the North Pole, as CFS predicts snow over sea ice). There are also many areas with a strong relationship between dSWE on 1 April and April-June dSWn, although the correlation is opposite: years with less initialized SWE in 1 April forecasts relative to 1 January forecasts lead to more positive values of April-June dSWn. There also exist significant correlations between dSWE on 1 April and April-June dSM, $\mathrm{dLH}, \mathrm{dSH}$, and dT2m; however, significant correlations involving $\mathrm{LH}$ have the most limited extent. These 

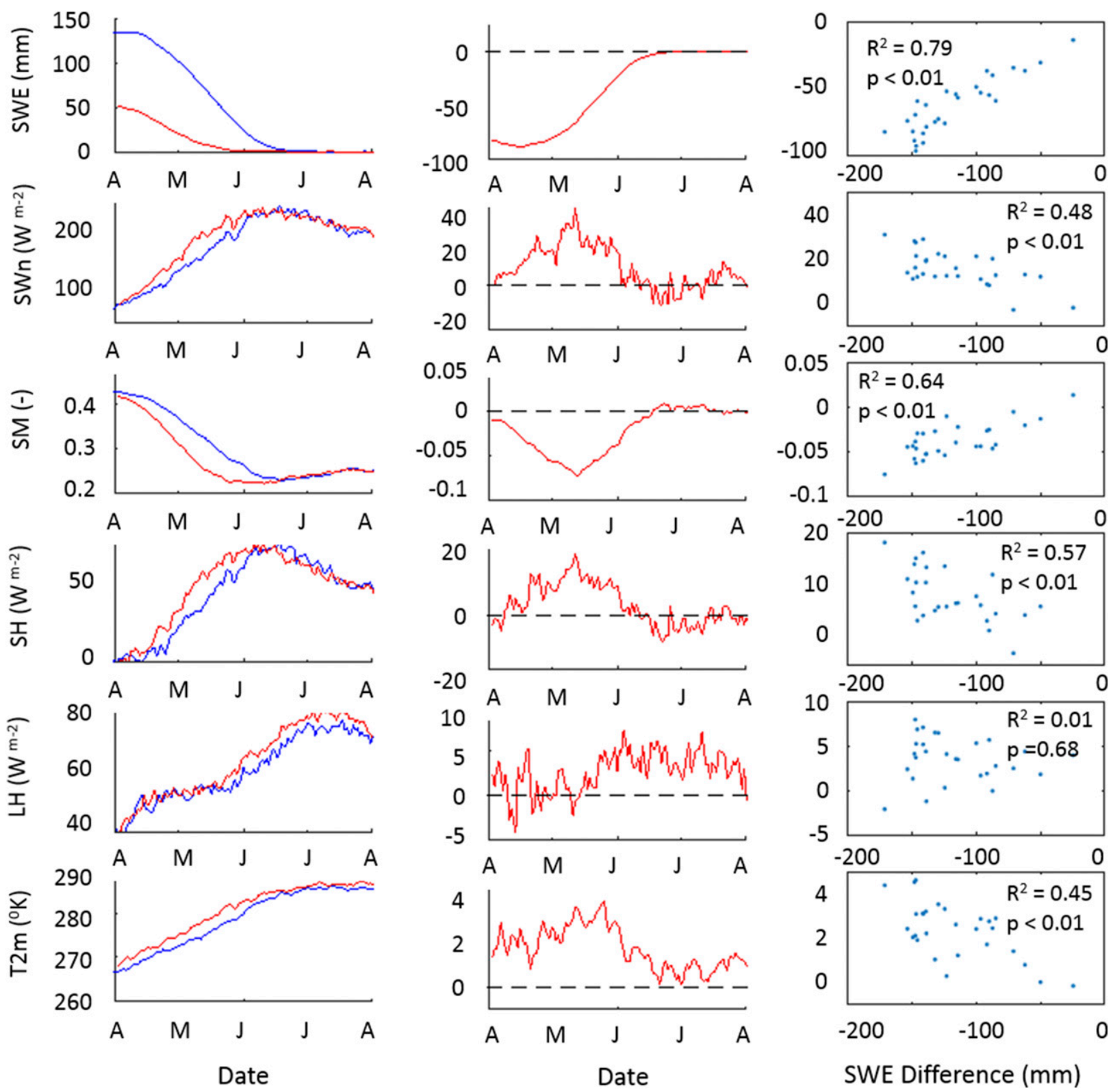

FIG. 3. (left) Average (from 1982-2009) seasonal progression (from April to August) of quantities from the 1 January (blue) and 1 April forecasts (red) for the $5^{\circ} \times 5^{\circ}$ box located over the northern Rockies in Fig. 1. (middle) Difference between the red and blue lines in the left column. (right) April-June mean differences of these variables between 1 April and 1 January forecasts in each year plotted against the 1 April SWE mean difference in the same year from 1982 to 2009 along with the associated $R^{2}$ (squared correlation coefficient) and $p$ values for each linear regression.

correlations (e.g., between dSWE on 1 April and AprilJune dSWn) are readily apparent when considering all of North America, Eurasia, and the entire Northern Hemisphere north of $30^{\circ}$ (Table 1). Again, April-June $\mathrm{dLH}$ is the only variable discussed so far that is not significantly correlated with dSWE on 1 April.

Just as energy balance variables differ between 1 January forecasts and 1 April forecasts, other model quantities also show differences as well. Figure 5 shows April-June dZ500, dSLP, dSST, and dPPT, averaged from 1982 to 2009. In general, 1 April forecasts have higher Z500 in the northern high latitudes, lower SLP over northern continental areas, higher SSTs in the northern oceans, and a northward displaced precipitation band [i.e., the intertropical convergence zone (ITCZ)]. Certainly not all of these changes between the 

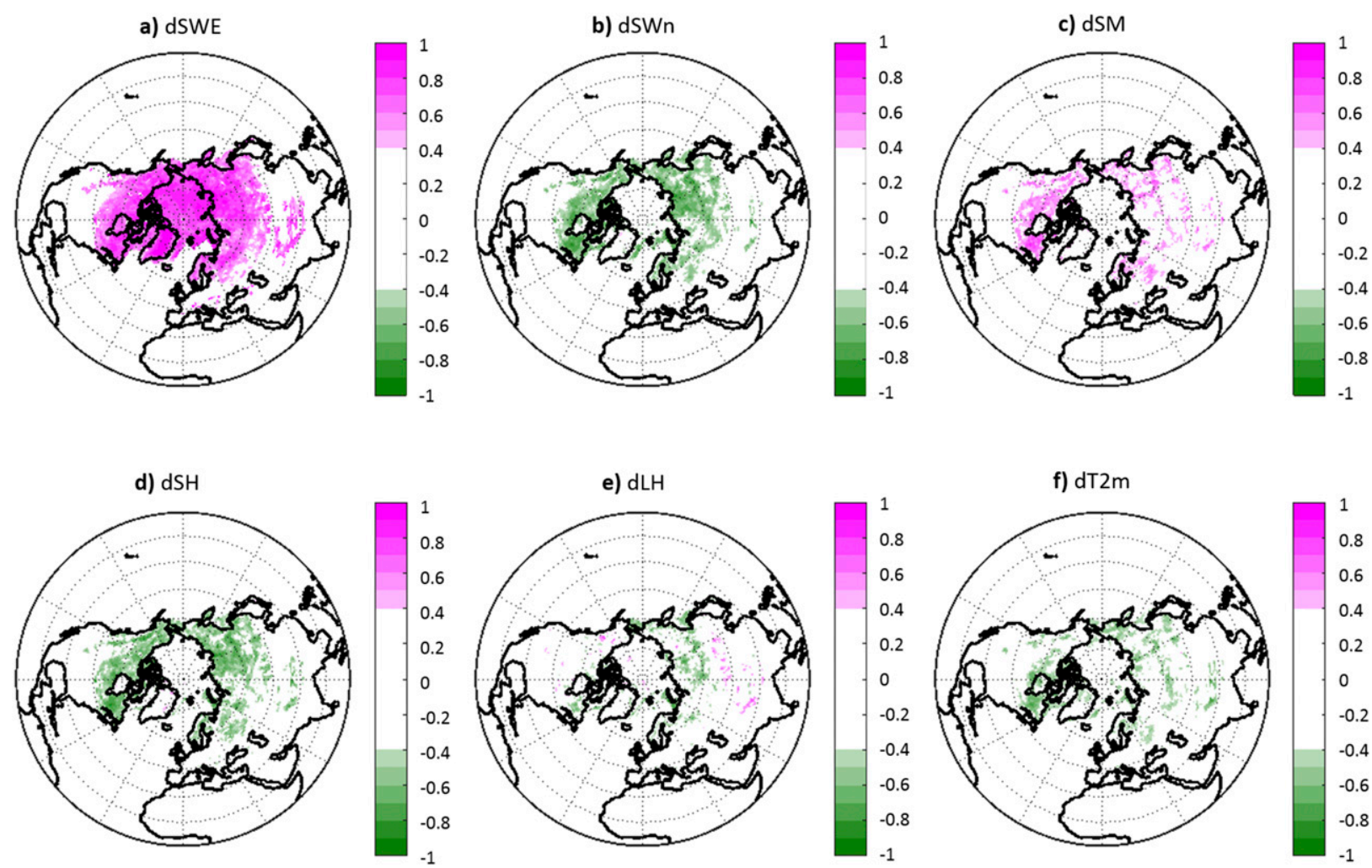

FIG. 4. Spatial maps showing the correlations (from 1982-2009) between dSWE on 1 April and April-June (a) dSWE, (b) dSWn, (c) dSM, (d) dSH, (e) dLH, and (f) dT2m between the 1 January and 1 April forecasts. The map colors represent the Pearson correlation coefficient $(r)$ between each relationship. Areas where $|r|<0.4$ (corresponding to a $p$ value of $\sim 0.035$ ) are shown as white.

1 January forecasts and 1 April forecasts can be attributed to changes in SWE, but some of these changes could be related.

While it is straightforward to understand the direct impact of dSWE on energy balance variables such as SWn and SH (as mentioned earlier), it is somewhat more difficult to attribute the differences in other variables, particularly those occurring outside of grid boxes with snow. For example, the effects of snow on the ground may influence atmospheric circulation downstream of the snow, and furthermore its influence may be diluted by other effects. As a result, there are generally poor correlations between dSWE and many of these variables on a grid box by grid box basis. As an example, Fig. S1 in the supplemental material shows that there are many small areas with a significant relationship between dSWE on 1 April and April-June difference in precipitation between the 1 April and 1 January forecasts (April-June dPPT). However, these relationships are not systematically positive or negative over large areas: in some places, dSWE on 1 April is correlated with less April-June dPPT, while in others it is correlated with more AprilJune dPPT. As a result, considering all of North
America, Eurasia, and the entire Northern Hemisphere north of $30^{\circ}$ (Table 1 ), there are weak correlations between dSWE on 1 April and April-June dPPT. Correlations between dSWE on 1 April and April-June dPPT

TABLE 1. Average Pearson correlation coefficients $(r)$ between area-averaged dSWE on 1 April and area-averaged April-June quantities (explained in the text) over land areas north of $30^{\circ} \mathrm{N}$. The first column shows these correlations considering all land areas north of $30^{\circ} \mathrm{N}$. The second column shows these correlations over just the North American continent (not including Greenland, but including islands in the Canadian Archipelago). The third column shows these correlations over just the Eurasian continent. Correlations that we consider to be statistically significant using the same criteria as in the rest of the manuscript $(r>0.4, p<\sim 0.035)$ are shown in bold.

\begin{tabular}{lrrr}
\hline & Entire Northern & & \\
& Hemisphere & North America & Eurasia \\
\hline dSWE & $\mathbf{0 . 9 1}$ & $\mathbf{0 . 8 1}$ & $\mathbf{0 . 7 6}$ \\
dSWn & $\mathbf{- 0 . 7 8}$ & $\mathbf{0 . 7 0}$ & $\mathbf{- 0 . 6 6}$ \\
dSM & $\mathbf{0 . 7 9}$ & $\mathbf{0 . 7 4}$ & $\mathbf{0 . 5 7}$ \\
dSH & $\mathbf{- 0 . 7 3}$ & $-\mathbf{0 . 7 4}$ & $\mathbf{- 0 . 6 5}$ \\
dLH & 0.32 & -0.04 & -0.18 \\
dT2m & $-\mathbf{0 . 7 7}$ & $-\mathbf{0 . 5 1}$ & $\mathbf{0 . 5 8}$ \\
dZ500 & $\mathbf{- 0 . 6 2}$ & -0.35 & $-\mathbf{0 . 4 8}$ \\
dSLP & 0.29 & 0.13 & 0.35 \\
dPPT & 0.10 & 0.33 & -0.03 \\
\hline
\end{tabular}



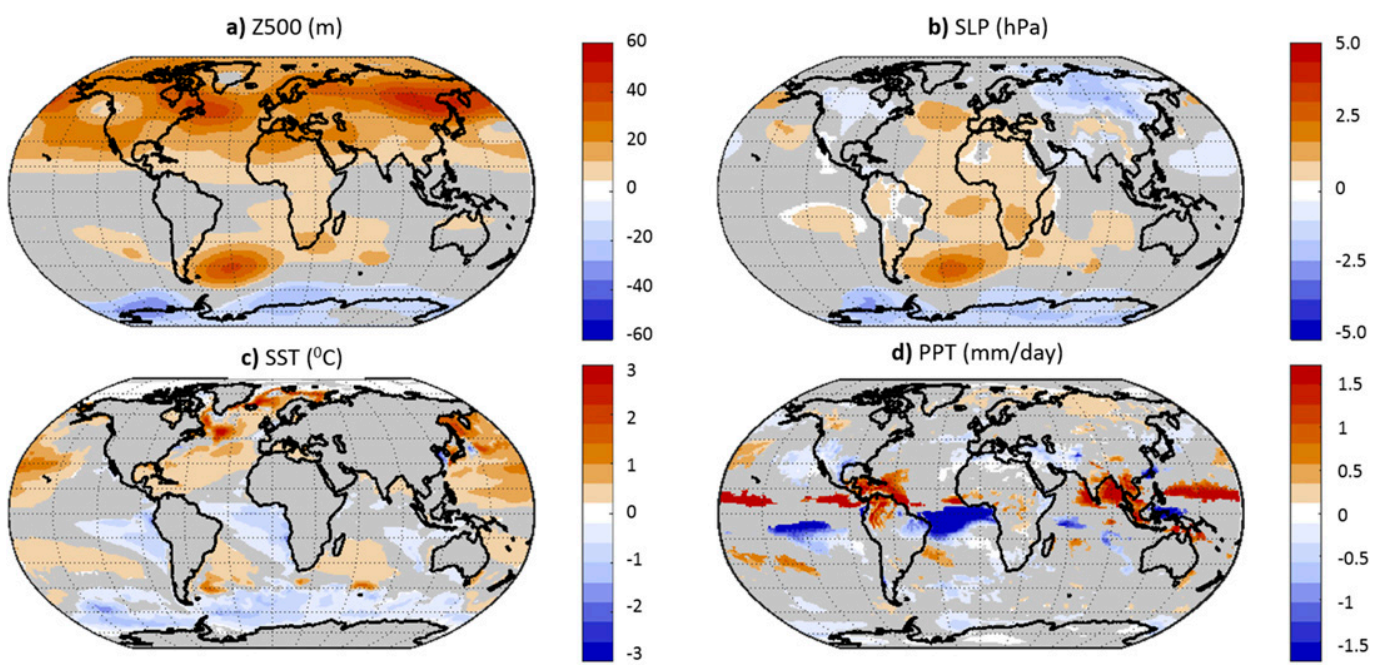

FIG. 5. Spatial maps showing the differences (averaged for all years from 1982 to 2009) of April-June values of (a) Z500, (b) SLP, (c) SST, and (d) PPT between 1 April and 1 January forecasts. Blue colors indicate that 1 April forecasts predict lower values and red colors indicate that the 1 April forecasts predict higher values than 1 January forecasts. Areas where the differences are not significant (using a two-tailed two-sample $t$ test with a $p$ value of 0.01) are shaded gray.

in the tropics, including the apparent northward shift of the ITCZ shown in Fig. 5, are equally as weak (not shown).

There is, however, a stronger correlation between dSWE on 1 April and April-June dZ500 (change in Z500 between 1 January forecasts and 1 April forecasts) (Table 1). Just like April-June dT2m, April-June dZ500 is negatively correlated with dSWE on 1 April. Physically the warmer temperatures associated with the smaller SWE in 1 April forecasts translate to greater geopotential thicknesses between the surface and $500 \mathrm{hPa}$ and hence overall greater Z500. The correlation between dSWE on 1 April and April-June dSLP (change of SLP between 1 January forecasts and 1 April forecasts) is also greater than that for dPPT, but both are not significant (Table 1 ). The correlation $(0.2)$ between dSWE on 1 April and April-June values of the North Atlantic Oscillation (computed as the difference between SLP for the CFS grid box closest to the Azores and that closest to Iceland, and representing an index of atmospheric circulation over the middle and high latitudes) is not significant either.

This suggests that there are also other factors besides SWE that are partly responsible for changes in some of the model variables between the 1 January and 1 April forecasts. Indeed, Fig. 5 shows that the warmth signal in the later forecasts, which, over land, seems to be caused by too little snow, extends significantly over the ocean in the Northern Hemisphere. Furthermore, there is a significant northward shift of the ITCZ in the later forecasts (relative to the earlier forecasts) that does not seem to correspond well with changes in dSWE. Perhaps, there are also systematic differences between the forecasts in terms of ocean state that are also causing enhanced warmth in the later forecasts over oceans (though at this time it is unclear if this is linked with the northward shift of the ITCZ in later forecasts). However, this does not necessarily mean that there are connections between ocean state and snow or other model variables over land. These connections (between April-June dSST, or the change in SST between 1 January forecasts and 1 April forecasts, dSWE on 1 April, and the change in other model variables during April-June) are discussed next.

\section{c. The role of the ocean}

Although there is good physical justification about the link between differences in SWE and differences in SWn, $\mathrm{SM}, \mathrm{LH}, \mathrm{SH}$, and $\mathrm{T} 2 \mathrm{~m}$ and, to a lesser degree, Z500 and PPT during the snowmelt period, differences in the ocean state during the forecast period could also influence these variables (especially T2m and Z500) as well. Figure 5c shows that 1 April forecasts generally have higher AprilJune SSTs in the northern high latitudes than 1 January forecasts. However, Fig. 6a shows that there are virtually no areas where April-June dSWE is significantly correlated with the average difference in April-June SSTs between 1 January forecasts and 1 April forecasts (AprilJune dSST) in the Northern Hemisphere (north of $30^{\circ} \mathrm{N}$ ). Figures $6 \mathrm{~b}-\mathrm{d}$ also show that there are few areas over land where April-June dT2m is significantly correlated with the average April-June dSST in the Northern Hemisphere. These results suggest that over land, the effect of 


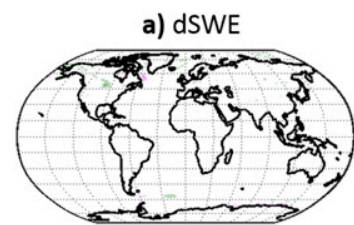

e) SWE anomaly
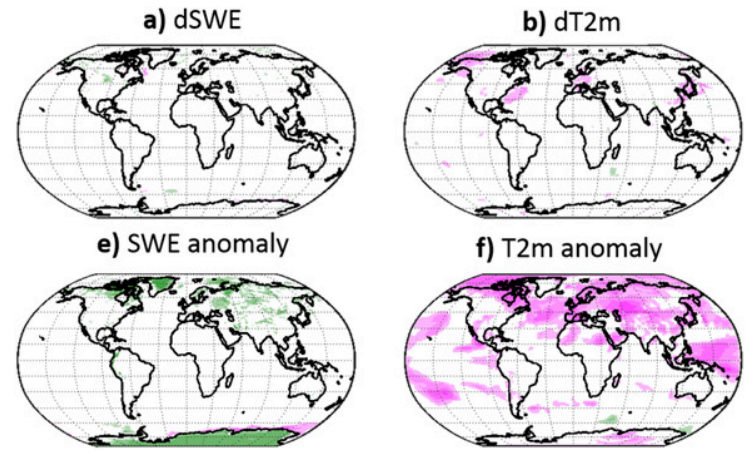

f) $\mathrm{T} 2 \mathrm{~m}$ anomaly

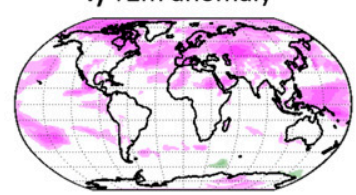

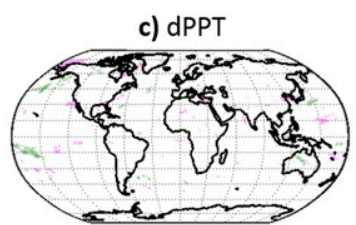

g) PPT anomaly

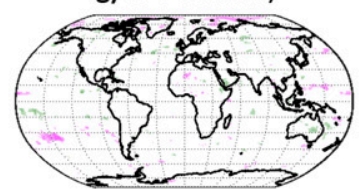

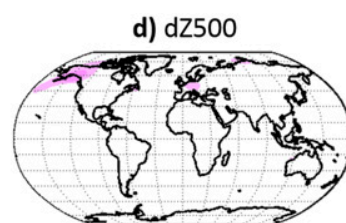

h) $Z 500$ anomaly

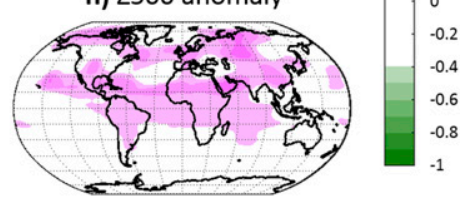

FIG. 6. (top) Pearson correlation coefficient ( $r$ ) between April-June dSST (for the Northern Hemisphere north of $30^{\circ}$ N) and April-June (a) dSWE, (b) dT2m, (c) dPPT, and (d) dZ500. (bottom) Pearson correlation coefficient ( $r$ ) between April-June SST anomalies (for the Northern Hemisphere north of $30^{\circ} \mathrm{N}$ ) and (e) April-June SWE anomalies, (f) T2m anomalies, (g) PPT anomalies, and (h) Z500 anomalies based on the 1 April forecasts. Areas where $|r|<0.4$ (corresponding to a $p$ value of $\sim 0.035$ ) are shown as white.

the reduced amount of snow in the 1 April forecasts (i.e., dSWE on 1 April) is much more important than SST differences between 1 April forecasts and 1 January forecasts. Note, however, that this does not mean that the ocean state itself does not affect these variables. For example, there is a stronger connection between SST anomalies (i.e., the difference with respect to the 19822009 climatology) and T2m anomalies (for April-June, computed from the 1 April forecast) than between AprilJune dSST and April-June dT2m (cf. Figs. 6b and 6f). Figure 6 also shows that the same is true for SWE, PPT, and $\mathrm{z} 500$.

The above analysis links the ocean state for the entire Northern Hemisphere to variables such as SWE and $\mathrm{T} 2 \mathrm{~m}$. However, because the linkage between the ocean and these variables is indirect over land (e.g., through teleconnections), we also focused on smaller areas (Fig. S2 in the supplemental material) with high interannual variability of SSTs (some of which are known to have connections with atmospheric teleconnection patterns). Figures S3-S7 show the relationship between April-June dSWE, dT2m, dPPT, and dZ500 with the average April-June dSST over these small areas. Again the main conclusion remains the same: April-June dSST differences between the 1 April and 1 January forecasts are minimally correlated with April-June dSWE, dT2m, dPPT, and dZ500 over most land areas, while SST anomalies have a larger correlation with $\mathrm{T} 2 \mathrm{~m}, \mathrm{Z} 500$, and, to a lesser degree, PPT and SWE anomalies based on the 1 April forecasts. Note also that the highest correlations between SST anomalies and anomalies of SWE, T2m, and dZ500 over continental regions in the Northern Hemisphere occur for the case when SSTs are averaged for the Northern Hemisphere north of $30^{\circ} \mathrm{N}$ (Fig. 6) instead of for the smaller regions (Figs. S3-S7 in the supplemental material).

Furthermore, we also examined whether the divergence of the April-June forecast values between 1 January forecasts and 1 April forecasts (i.e., the differences that are shown in Fig. 2) are more or less prominent under different SST regimes. Overall, we find that there is relatively little difference. For example, Table 2 (columns 1-3) shows that over land at high latitudes dSWE on 1 April is negative and of about the same magnitude for years with a positive Pacific decadal oscillation (PDO) index (Mantua et al. 1997) as for years with a negative PDO index. Likewise, dSWn, dSH, and $\mathrm{dT} 2 \mathrm{~m}$ for April-June are positive, and of about the same

TABLE 2. Columns 1-3 show averaged differences of quantities for April-June over land areas north of $60^{\circ} \mathrm{N}$ between $1 \mathrm{January}$ forecasts and 1 April forecasts for all years from 1982-2009, for years when the average springtime (April-June) PDO index was above 0.5 (PDO + years) (for a total of $14 \mathrm{yr}$ ), and when it was below -0.5 (PDO - years) (for a total of 6 yr). Column 4 shows the correlation squared $\left(R^{2}\right)$ between each of the differences (e.g., April-June dSWE) and the springtime PDO index itself. For comparison, column 5 shows $R^{2}$ between each of the differences and the aerially averaged dSWE on 1 April.

\begin{tabular}{|c|c|c|c|c|c|}
\hline & All years & $\mathrm{PDO}+$ & $\mathrm{PDO}-$ & $R^{2} \mathrm{w} / \mathrm{PDO}$ & $R^{2} \mathrm{w} / \mathrm{dSWE}$ \\
\hline $\mathrm{dSWE}(\mathrm{mm})$ & -46.72 & -44.32 & -54.09 & 0.14 & \\
\hline $\mathrm{dSWn}\left(\mathrm{W} \mathrm{m}^{-2}\right)$ & 15.13 & 14.15 & 18.22 & 0.11 & 0.67 \\
\hline dSM (unitless) & -0.02 & -0.02 & -0.03 & 0.10 & 0.40 \\
\hline $\mathrm{dSH}\left(\mathrm{W} \mathrm{m}^{-2}\right)$ & 7.16 & 6.83 & 8.82 & 0.09 & 0.51 \\
\hline $\mathrm{dLH}\left(\mathrm{W} \mathrm{m}^{-2}\right)$ & 1.72 & 1.76 & 1.25 & 0.06 & 0.01 \\
\hline $\mathrm{dT} 2 \mathrm{~m}\left({ }^{\circ} \mathrm{C}\right)$ & 2.60 & 2.39 & 2.93 & 0.09 & 0.60 \\
\hline
\end{tabular}


magnitude, regardless of whether they are grouped according to PDO. April-June dSM is always slightly negative, and April-June dLH is always slightly positive over land at high latitudes. Furthermore, there is a relatively low correlation between the PDO index and any of these measures (Table 2, column 4). For comparison, the correlation between dSWE on 1 April and dSWn, $\mathrm{dSM}, \mathrm{dSH}, \mathrm{dLH}$, and dT2m for April-June are much higher (Table 2, column 5). We performed similar analyses with other ocean indices as well [e.g., El NiñoSouthern Oscillation (ENSO) index; not shown], but in all cases, the model differences are not much influenced by the SST configuration.

The fact that $\mathrm{dT} 2 \mathrm{~m}$ over land is affected much more strongly by dSWE than by dSST underscores the need to consider the important role of snow as a slow varying component of the Earth system that could contribute skill to subseasonal-to-seasonal (S2S) prediction. As has been pointed out in some previous studies (e.g., Orsolini et al. 2013; Jeong et al. 2013), this is analogous to the well-known soil moisture-atmosphere coupling that has been identified in previous studies to provide predictability in some "hot spots" (e.g., Koster et al. 2004). Here, we suggest that proper initialization of the snowpack could be very important for seasonal prediction during the spring-summer transition in the snowy regions.

\section{d. How does snow initialization affect the quality of CFS forecasts?}

The CFS forecasts initialized earlier in the snow season appear to be better in terms of their prediction of SWE than those initialized later in the snow season, largely for the reasons discussed in section $3 \mathrm{a}$. When compared to the reference snow dataset developed by Broxton et al. (2016a), it is clear that forecasts initialized later in the year predict far too little SWE (bottom panels of Fig. 1). Of the three boxes over the United States shown in Fig. 1 (from west to east, centered in Idaho, Wisconsin, and Maine), the Idaho and Maine boxes show the biggest underestimations by the later forecasts, although the Wisconsin box also shows a substantial underestimation for later forecasts. For example, the 1 March forecasts initialize SWE to be $11 \%$, $10 \%$, and $26 \%$ of observed SWE (from the UA data) in the Idaho, Maine, and Wisconsin boxes, respectively. These results agree with our previous studies (Broxton et al. 2016b; Dawson et al. 2016), which find that there is not enough SWE in the CFSR (which provides initial conditions for CFS-RR) and that SWE initialization in the operational CFS (which is the same as the procedure used in CFS-RR) has serious deficiencies. In general, 1 January forecasts tend to be better at representing the
SWE climatology depicted in the Broxton et al. (2016a) dataset.

Note that although global SWE datasets exist, these data are not used here to evaluate the CFS results because we have found the quality of these data to be low. For example, we evaluated SWE data based on coarse-scale $\left(>0.25^{\circ}\right)$ atmospheric reanalyses and the Global Land Data Assimilation System and found that all of these products severely underestimate SWE in areas with high SWE (Broxton et al. 2016b). Our ongoing study finds that this underestimate is also true for satellite remotely sensed SWE. In addition, we have identified other limitations with these data, such as the poorer quality of the remotely sensed data in areas with trees, as well as the especially large underestimates of SWE in mountainous areas in all datasets.

While earlier forecasts have more realistic values of SWE, later forecasts perform much better in terms of $\mathrm{T} 2 \mathrm{~m}$. Figure $7 \mathrm{~b}$ shows that when compared with the Wang and Zeng (2013) T2m data over land, 1 January forecasts have widespread April-June T2m biases throughout the Northern Hemisphere; in particular, forecasted temperature is far too low, especially over northern Eurasia. Conversely, 1 April forecasts simulate April-June T2m to be much warmer (as shown in the bottom row of Fig. 3), and hence have much smaller T2m biases (Fig. 7c). The later forecasts also have much higher skill than earlier ones as there is a much higher correlation between $\mathrm{T} 2 \mathrm{~m}$ for this period predicted from the 1 April forecasts and the Wang and Zeng (2013) data than that between the 1 January forecasts and the Wang and Zeng (2013) data (Figs. 7d,e). Some of this is simply a reflection of better performance for shorter lead times, but changes in the initial snow state also play some role, as there are significant correlations between the difference between how well the forecasts relate to the Wang and Zeng (2013) data (measured as the difference between Figs. 7d and 7e) and dSWE on 1 April (Fig. 7f). Note in Fig. 7f that areas of positive correlation cover much of the snowy region of the Northern Hemisphere, although in most cases the strength of these correlations is weaker than the $r=0.4$ cutoff (corresponding with a $p$ value of $\sim 0.035$ ) that we consider to be statistically significant, and hence are shaded as white.

\section{Discussion and conclusions}

Because SWE in CFS-RR (and CFSv2) is initialized with external data sources instead of cycled between forecasts (i.e., initialized SWE for a given forecast is not the same as SWE that is predicted by a previous forecast), there are differences between the evolution of 

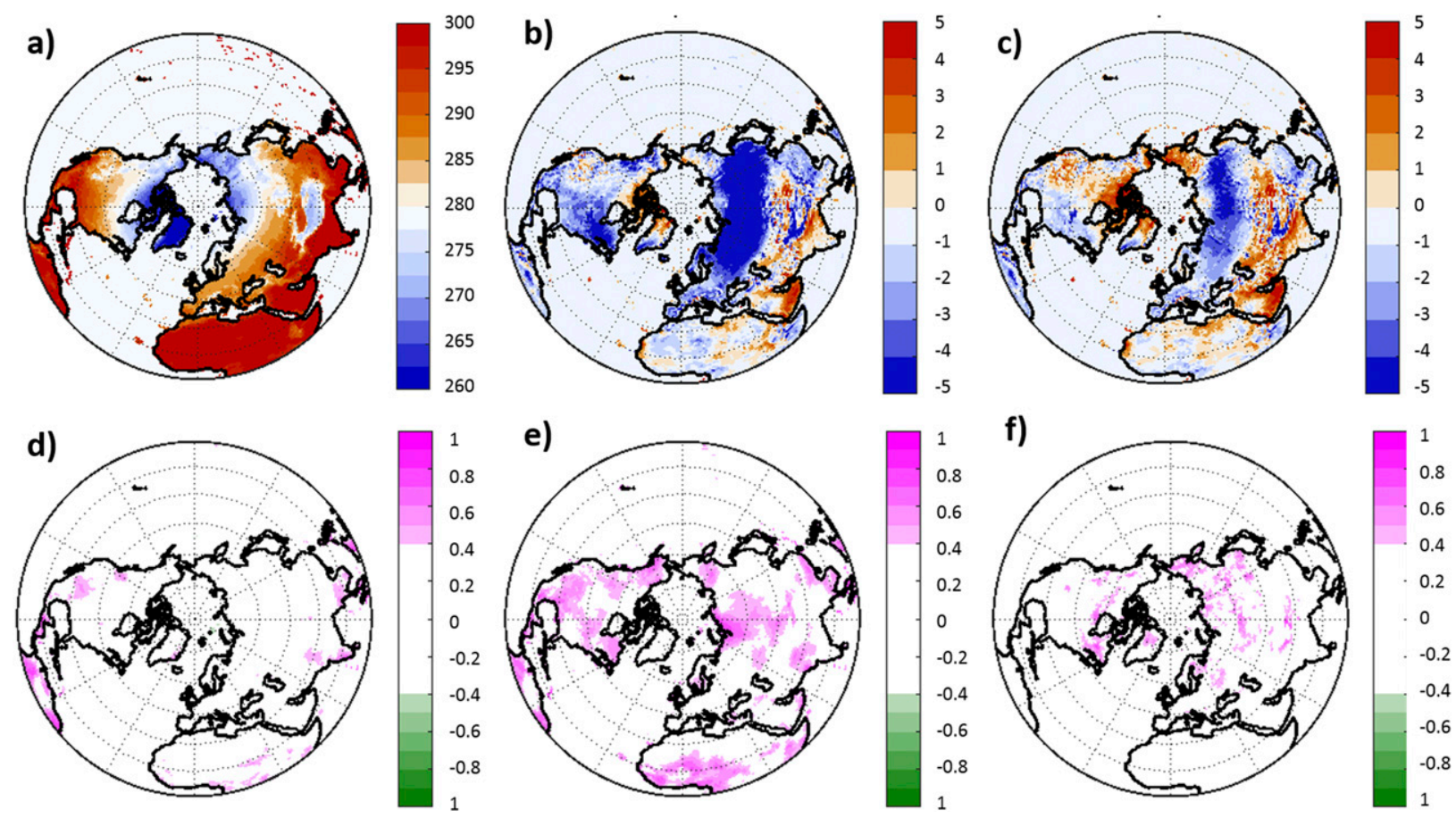

FIG. 7. (a) The 28-yr average of April-June T2m (K) for Northern Hemisphere land areas based on the Wang and Zeng (2013) data. (b) The 28-yr average difference in April-June T2m (K) between the 1 January forecasts and the Wang and Zeng (2013) data. (c) As in (b), but using the 1 April forecasts. (d) Pearson correlation coefficient ( $r$ ) between detrended April-June T2m predicted from 1 January forecasts and from the Wang and Zeng (2013) data based on all $28 \mathrm{yr}$ of data. (e) As in (d), but using the 1 April forecasts. (f) Correlation coefficient between dSWE on 1 April and the increase in forecast skill between 1 January forecasts and 1 April forecasts [i.e. (e) - d)]. In (d)-(f), areas where $|r|<0.4$ (corresponding to a $p$ value of $\sim 0.035$ ) are shown as white.

SWE between earlier and later forecasts. Notably, in many places, SWE is initialized to be much lower in later forecasts than is simulated in the earlier forecasts, and therefore the subsequent SWE is lower as well (Fig. 1). In our previous studies (e.g., Dawson et al. 2016), we have found that SWE initialization in NCEP's operational models (including CFS) is too low. The same can be said of the CFS-RR. Comparison with observed SWE data over the United States indicates that SWE initialized in later forecasts tends to be too low, even worse than SWE predicted from earlier forecasts (Fig. 1). In other words, CFS-RR predicts SWE better when it is free-running from an initial state early in the season than from an initial state late in the season.

These SWE differences translate to forecast differences in other quantities as well. For example, AprilJune $\mathrm{T} 2 \mathrm{~m}$ from the $1 \mathrm{January}$ forecasts is over $2^{\circ} \mathrm{C}$ colder on average over much of northern Eurasia than that from the 1 April forecasts (Fig. 2). This includes areas where April-June SWE is much higher in the 1 January forecasts than the 1 April forecasts. Furthermore, there are also significant correlations between dSWE on 1 April and April-June dT2m (Fig. 4). For instance, years with a highly negative dSWE on 1 April (i.e., much more snow in the 1 January forecasts) have a higher April-June dT2m (i.e., much colder in the 1 January forecasts), indicated by the negative correlation shown in Fig. 4f. These correlations also exist for other forecast quantities as well (e.g., SWnet, SM, SH, Z500). We found some connections between dSWE on 1 April and April-June dPPT, although in general this connection is inconsistent over large areas (e.g., positive dSWE on 1 April may be correlated with positive April-June dPPT in some areas, but it may be correlated with negative April-June dPPT in adjacent areas).

The connections that we found between SWE differences and differences involving other forecast quantities in the earlier versus later forecasts generally make physical sense. It would appear that the main impact of having less SWE in the later forecasts is having earlier and smaller snowmelt in the later forecasts. This greatly impacts both the albedo of the land surface as well as the soil moisture. The lower albedo in the April-June period that is associated with earlier snowmelt translates to higher SWn, as less incoming radiation is reflected. More radiation is absorbed by the land surface, which in turn heats it, and affects the turbulent exchange of energy with the atmosphere. This is why sensible heating is 
affected in the same way: lower SWE translates into higher sensible heat flux, which increases near-surface temperatures. The other main impact of having less SWE in the later forecasts (and earlier and smaller snowmelt) is that less water enters the soil earlier in the season (hence affecting soil moisture). In many areas, this translates to drier soils from April-June, leading to reduced latent heat flux (Figs. 2 and 4). In other areas where the soil is not dry (e.g., in the northern high latitudes), however, the increased SWn leads to increased latent heat flux.

The impact of snow on quantities (e.g., PPT) over regions not covered with snow has been emphasized in some previous studies. For instance, high snow years over the Himalayan-Tibetan Plateau (HTP) are found to have a delayed monsoon onset in the Indian subcontinent region (ISR) (Saha et al. 2013; Senan et al. 2016). The positive correlations between dSWE on 1 April and April-June dZ500 in our study suggest that this snow-monsoon connection is certainly possible through atmospheric teleconnection. Quantitatively, however, the correlations between SWE patterns and PPT patterns are low (Fig. S1) despite the large differences between the 1 January and 1 April PPT forecasts in some areas (Fig. 5). We have also further tested the connection between dSWE on 1 April over the HTP and dPPT in the ISR. Although 1 April forecasts generally have lower SWE over the HTP and higher PPT over the ISR than do 1 January forecasts, we do not find a statistically significant correlation between dSWE on 1 April over the HTP and May dPPT over the ISR (Fig. S8), which is around the time of the onset of the Indian monsoon. Similarly, the correlation between the 1 April SWE anomaly over the HTP and May PPT anomaly over the ISR (based on the 1 April forecasts) is not statistically significant (although, interestingly, we do find a significant correlation between 1 April SWE anomaly over the HTP and April PPT anomaly over the ISR).

Although much of the impact on especially the energy balance variables is primarily due to snow, the ocean potentially has some impact as well. In particular, some of the warmth signal, whereby later forecasts are warmer than earlier forecasts, which extends out over the oceans away from the continents might be due to inconsistencies in ocean state between earlier and later forecasts. Indeed, we find a connection between SST anomalies and anomalies of T2m, Z500, and, to a much lesser degree, PPT and SWE based on the 1 April forecasts (e.g., the interannual variability of Northern Hemisphere SSTs is significantly correlated with the interannual variability of $\mathrm{T} 2 \mathrm{~m}$ over much of Eurasia; Fig. 6). However, there are far fewer areas of widespread significant correlations involving dSST versus dT2m, dZ500, dPPT, and dSWE, especially in the interiors of continents, than with dSWE (Figs. 4 and 6). In other words, dSST has much less impact than dSWE (on 1 April) on the seasonal forecasts for April-June, despite the strong correlation of the interannual variability of SST in April-June with that of other quantities.

Furthermore, SST-based indices such as PDO and ENSO indices are not very highly correlated with interannual variability of April-June dT2m, dZ500, dPPT, and dSWE (between the 1 January forecasts and 1 April forecasts), certainly when compared with the correlations involving dSWE on 1 April (Table 2). The greater impact of dSWE than dSST (on 1 April) on dT2m during the spring-summer transition in many snowy areas is analogous to the well-known impacts of SM on the atmosphere in hot spots around the globe (e.g., Koster et al. 2004). This also suggests the major role of snowpack in seasonal forecasting during the spring-summer transition, and the importance of proper initialization of snow in seasonal prediction models.

A primary effect of having less SWE in the later forecasts than the earlier forecasts is that $\mathrm{T} 2 \mathrm{~m}$ in the later forecasts shows less of a cold bias (as well as higher skill) than it does in the earlier forecasts (Fig. 7). However, as mentioned earlier, SWE for this period is worse in later forecasts than in earlier forecasts. This mismatch suggests that the better temperature forecasts in the later forecasts occur for the wrong reasons (i.e., they occur despite the worse SWE forecasts). At the same time, this indicates that simply fixing the SWE initialization, without fixing other model deficiencies that allow the mismatch to occur in the first place, will likely not improve or even worsen model forecasts.

In general, this issue indicates deficiencies in the atmospheric component (e.g., radiative transfer) and/or land component (e.g., snow parameterizations, turbulence under stable conditions) in CFSv2. Previous studies have identified the CFS treatment of albedo over snowcovered surfaces to be problematic in different environments with different vegetation characteristics (Livneh et al. 2010; Wang and Zeng 2010; Wang et al. 2010). This deficiency could lead to the early snowmelt in the 1 January forecasts and 1 April forecasts, but it would not lead to the better April-June T2m forecasts from a worse snow initialization (on 1 April) by itself. A more likely reason is the CFS deficiencies in the atmospheric processes (e.g., radiative transfer) that provide compensating errors for the initialized shallow snowpack (in the 1 April forecasts) and, to a lesser degree, for the CFS deficiencies in the snow parameterization. Other aspects governing the atmospheric circulation (which also controls the temperature field) may also be the culprit. The solution 
requires the collaboration of CFS developers with the research community to improve the snow initialization in CFS first, followed by the improvement of snow parameterization in its land component, and then most importantly for research-to-operation transition, followed by the revision/improvement of processes in the CFS atmosphere component (including radiative transfer, clouds, and aerosols).

Finally, as mentioned in the introduction, this study provides justification for a rigorous model sensitivity study in the future. For instance, to isolate the snow initialization impact on CFS forecasting from the ocean impact (i.e., to determine which factor most influences forecast quantities in different regions), CFS could be rerun with three different initial conditions on 1 April: 1 ) default 1 April initialization of atmosphere, ocean, and land; 2) replacing the default land state by that on 1 April from the 1 January forecast; and 3 ) replacing the default ocean state by that on 1 April from the 1 January forecast. Here, it was advantageous to use the large catalogue of already generated model quantities from NCEP as it is much less time consuming than full model sensitivity tests. Furthermore, sensitivity tests with the initializations 2 and 3 above also have difficulties of their own, such as the model adjustment of atmosphere, ocean, and land components that are not in equilibrium at the initial state. Studies similar to our analysis here can be done for operational models at other weather and climate prediction centers to better direct their future model sensitivity studies as well. Together, these sensitivity tests using different operational models would further quantify the role of snowpack in seasonal forecasting during the spring-summer transition.

Acknowledgments. This study is funded by NASA (Grant NNX14AM02G). CFS-RR data used in this study are obtained from the NOAA National Operational Model Archive and Distribution System (http:// nomads.ncdc.noaa.gov/). We thank three reviewers for constructive and helpful comments and suggestions. Global corrected temperature data from Wang and Zeng (2013) were downloaded from the NCAR Research Data Archive (http://rda.ucar.edu/datasets/ds193.0/), and PRISM-based SWE data were generated following the methods described in Broxton et al. (2016a) and Broxton et al. (2016b).

\section{REFERENCES}

Air Force Weather Agency, 2013: Algorithm description document for the Air Force Weather Agency Snow Depth Analysis Model. AFWA Rep., 10 pp.

Betts, A. K., R. Desjardins, D. Worth, S. Wang, and J. Li, 2014: Coupling of winter climate transitions to snow and clouds over the Prairies. J. Geophys. Res. Atmos., 119, 1118-1139, doi:10.1002/2013JD021168.

Broxton, P. D., N. Dawson, and X. Zeng, 2016a: Linking snowfall and snow accumulation to generate spatial maps of SWE and snow depth. Earth Space Sci., 3, 246-256, doi:10.1002/2016EA000174.

— X. Zeng, and N. Dawson, 2016b: Why do global reanalyses and land data assimilation products underestimate snow water equivalent? J. Hydrometeor., 17, 2743-2761, doi:10.1175/ JHM-D-16-0056.1.

Chen, D., S. E. Zebiak, A. J. Busalacchi, and M. A. Cane, 1995: An improved procedure for El Niño forecasting: Implications for predictability. Science, 269, 1699-1702, doi:10.1126/ science.269.5231.1699.

Clark, M. P., and M. C. Serreze, 2000: Effects of variations in East Asian snow cover on modulating atmospheric circulation over the North Pacific Ocean. J. Climate, 13, 3700-3710, doi:10.1175/ 1520-0442(2000)013<3700:EOVIEA > 2.0.CO;2.

Cohen, J., and D. Entekhabi, 1999: Eurasian snow cover variability and Northern Hemisphere climate predictability. Geophys. Res. Lett., 26, 345-348, doi:10.1029/1998GL900321.

— , and Coauthors, 2014: Recent Arctic amplification and extreme mid-latitude weather. Nat. Geosci., 7, 627-637, doi:10.1038/ ngeo2234.

Dawson, N., P. D. Broxton, X. Zeng, M. Leuthold, M. Barlage, and P. Holbrook, 2016: An evaluation of snow initializations for NCEP global and regional forecasting models. J. Hydrometeor., 17, 1885-1901, doi:10.1175/JHM-D-15-0227.1.

Decker, K. L. M., D. Wang, C. Waite, and T. Scherbatskoy, 2003: Snow removal and ambient air temperature effects on forest soil temperatures in northern Vermont. Soil Sci. Soc. Amer. J., 67, 1234-1242, doi:10.2136/sssaj2003.1234.

Douville, H., 2010: Relative contribution of soil moisture and snow mass to seasonal climate predictability: A pilot study. Climate Dyn., 34, 797-818, doi:10.1007/s00382-008-0508-1.

Francis, J. A., W. Chan, D. J. Leathers, J. R. Miller, and D. E. Veron, 2009: Winter Northern Hemisphere weather patterns remember summer Arctic sea-ice extent. Geophys. Res. Lett., 36, L07503, doi:10.1029/2009GL037274.

Gong, G., D. Entekhabi, J. Cohen, and D. Robinson, 2004: Sensitivity of atmospheric response to modeled snow anomaly characteristics. J. Geophys. Res., 109, D06107, doi:10.1029/ 2003JD004160.

Gutzler, D. S., and J. W. Preston, 1997: Evidence for a relationship between spring snow cover in North America and summer rainfall in New Mexico. Geophys. Res. Lett., 24, 2207-2210, doi:10.1029/97GL02099.

Hahn, D. G., and J. Shukla, 1976: An apparent relationship between Eurasian snow cover and Indian monsoon rainfall. $J$. Atmos. Sci., 33, 2461-2462, doi:10.1175/1520-0469(1976)033<2461: AARBES $>2.0 . \mathrm{CO} ; 2$.

Jeong, J. H., H. W. Linderholm, S.-H. Woo, C. Folland, B.-M. Kim, S.-J. Kim, and D. Chen, 2013: Impact of snow initialization on subseasonal forecasts of surface air temperature for the cold season. J. Climate, 26, 1956-1972, doi:10.1175/JCLI-D-12-00159.1.

Koster, R. D., and Coauthors, 2004: Regions of strong coupling between soil moisture and precipitation. Science, 305, 11381140, doi:10.1126/science.1100217.

Krishnamurti, T. N., G. D. Rohaly, and H. S. Bedi, 1994: On the improvement of precipitation forecast skill from physical initialization. Tellus, 46A, 598-614, doi:10.3402/tellusa.v46i5.15647.

Livneh, B., Y. Xia, K. Mitchell, M. Ek, and D. Lettenmaier, 2010: Noah LSM snow model diagnostics and enhancements. J. Hydrometeor., 11, 721-738, doi:10.1175/2009JHM1174.1. 
Mantua, N. J., S. R. Hare, Y. Zhang, J. M. Wallace, and R. C. Francis, 1997: A Pacific interdecadal climate oscillation with impacts on salmon production. Bull. Amer. Meteor. Soc., 78, 1069-1079, doi:10.1175/1520-0477(1997)078<1069: APICOW $>2.0 . \mathrm{CO} ; 2$.

Mote, T. L., 2008: On the role of snow cover in depressing air temperature. J. Appl. Meteor. Climatol., 47, 2008-2022, doi:10.1175/2007JAMC1823.1.

Mudryk, L. R., C. Derksen, P. J. Kushner, and R. Brown, 2015: Characterization of Northern Hemisphere snow water equivalent datasets, 1981-2010. J. Climate, 28, 8037-8051, doi:10.1175/JCLI-D-15-0229.1.

Orsolini, Y. J., R. Senan, G. Balsamo, F. J. Doblas-Reyes, F. Vitart, A. Weisheimer, A. Carrasco, and R. E. Benestad, 2013: Impact of snow initialization on sub-seasonal forecasts. Climate Dyn., 41, 1969-1982, doi:10.1007/s00382-013-1782-0.

Peings, Y., H. Douville, R. Alkama, and B. Decharme, 2011: Snow contribution to springtime atmospheric predictability over the second half of the twentieth century. Climate Dyn., 37, 9851004, doi:10.1007/s00382-010-0884-1.

Saha, S., and Coauthors, 2006: The NCEP Climate Forecast System. J. Climate, 19, 3483-3517, doi:10.1175/JCLI3812.1.

- and Coauthors, 2010: The NCEP Climate Forecast System Reanalysis. Bull. Amer. Meteor. Soc., 91, 1015-1057, doi:10.1175/2010BAMS3001.1.
— , and Coauthors, 2014: The NCEP Climate Forecast System version 2. J. Climate, 27, 2185-2208, doi:10.1175/JCLI-D-12-00823.1.

Saha, S. K., S. Pokhrel, and H. S. Chaudhari, 2013: Influence of Eurasian snow on Indian summer monsoon in NCEP CFSv2 freerun. Climate Dyn., 41, 1801-1815, doi:10.1007/s00382-012-1617-4.

Senan, R., and Coauthors, 2016: Impact of springtime HimalayanTibetan Plateau snowpack on the onset of the Indian summer monsoon in coupled seasonal forecasts. Climate Dyn., 47, 2709-2725, doi:10.1007/s00382-016-2993-y.

Wang, A., and X. Zeng, 2013: Development of global hourly $0.5^{\circ}$ land surface air temperature datasets. J. Climate, 26, 7676-7691, doi:10.1175/JCLI-D-12-00682.1.

Wang, Z., and X. Zeng, 2010: Evaluation of snow albedo in land models for weather and climate studies. J. Appl. Meteor. Climatol., 49, 363-380, doi:10.1175/2009JAMC2134.1.

and M. Decker, 2010: Improving snow processes in the Noah land model. J. Geophys. Res., 115, D20108, doi:10.1029/ 2009JD013761.

$\mathrm{Xu}$, L., and P. Dirmeyer, 2011: Snow-atmosphere coupling strength in a global atmospheric model. Geophys. Res. Lett., 38, L13401, doi:10.1029/2011GL048049.

Yang, S., K.-M. Lau, and K.-M. Kim, 2002: Variations of the East Asian jet stream and Asian-Pacific-American winter climate anomalies. J. Climate, 15, 306-325, doi:10.1175/ 1520-0442(2002)015<0306:VOTEAJ >2.0.CO;2. 